\title{
Effect of Variety, Age and Sex in Some Productive Traits in Japanese Quail in Iraq
}

\author{
Khalid Hamid Hassan, Ali Rafea Abd - Alsattar, Homam Abed Alkareem Yassen, \\ Haeder Thier Abed, Dalal Abed Alrazak Abdul Wahab
}

Dept. of Animal Resources, College of Agriculture, University of Diyala, Baquba, Iraq

Email address:

Khaled@agriculture.uodiyala.edu.iq (K. H. Hassan)

\section{To cite this article:}

Hassan Khalid Hamid, Ali Rafea Abd - Alsattar, Homam Abed Alkareem Yassen, Haeder Thier Abed, Dalal Abed Alrazak Abdul Wahab. Effect of Variety, Age and Sex in Some Productive Traits in Japanese Quail in Iraq. American Journal of Bio Science.

Vol. 3, No. 2, 2015, pp. 55-58. doi: 10.11648/j.ajbio.20150302.15

\begin{abstract}
Background: There are many varieties of Japanese quail were reared in Iraq for both egg and meat production purpose. The variety classification was according to the color of plumage. Background: The study was conducted in poultry farm of Animal Resources - College of Agriculture - University of Diyala - Iraq, to compare two varieties of Japanese quail, white plumage quail and Gray plumage quail for their performance in meat production and some measurements of vital organs. Materials and Methods: The experimental units were 36 birds slaughtered at ages 6, 8 and 10 week of age, and measurements took for the following traits : live body weight, carcass weight, dress percentage, breast part weight, thigh weight, heart weight, liver weight, gizzard weight and total intestine length. The experiment performed according to $2 \times 2 \times 3$ factorial experiment in randomized complete block design with three replicates. Results: the results showed that there were highly significant differences among males and females in body weight, dress percentage, gizzard weight, liver weight and intestine length. The white variety has the relative heart weight significantly greater than gray variety. There were significant effect of age $\times$ variety interaction on gizzard weight, besides significant effect of age $\times$ sex on liver weight.
\end{abstract}

Keywords: Japanese Quail, Varieties, Dress Percentage, Carcass Parts Weight

\section{Introduction}

Although worlds poultry industry depends mainly on chickens production for both meat and egg, now there is an interesting in other poultry species for food production or genetic conservation resources purpose ${ }^{1}$.

Japanese quail represents important species for commercial production of egg and meat because of his unique traits such as fast growth and high rate of egg production ${ }^{2}$. There are many studies conducted in Iraq about viability and production performance of Japanese quail in the natural environment exhibited high adaptation for Iraqi conditions ${ }^{3}$. Hassan et al. ${ }^{4}$ reported in their study that the age has highly significant effect in body weight, carcass weight, intestine length, also there was significant effect of age in thigh weight, and the sex has significant effect in body weight, dress percentage., intestine length, liver weight percentage.

Daikwo et al. ${ }^{5}$ reported $72.36 \%$ an average dressing percentage in Japanese quail, and the measurements of carcass weight, breast weight, thigh weight, liver weight, heart weight and gizzard weight, their records were 90.01, 29.73, 6.44, 2.39, 1.15 and 2.67 respectively. Nasrollah et al. ${ }^{6}$ reported that there were significant differences among strains of quail in body weight, egg weight at different ages, and present highly significant interaction of strain, age and sex for egg weight and body weight. In the same direction Vali et al. ${ }^{7}$ reported that carcass weight, carcass percent, breast weight and thigh percentage, these records were significantly affected by strain. Berri et al. ${ }^{8}$ referred that the quality of poultry meat may be effected by many factors, such as age, sex, breed and slaughter conditions. The aim of this study is to determine the best variety included in the study and the variation of age and sex effect in different varieties.

\section{Materials and Methods}

The experiment was carried out in poultry house of Department of Animal Resources - College of Agriculture University of Diyala / Iraq. The experimental units were 36 
day-old Japanese quails, belong to White and Gray plumage recognized as two varieties, the variety classification was, according to plumage color ${ }^{1}$, the birds divided into three groups, each group of 12 birds of equal sex number, these groups reared to various ages 6,8 and 10 weeks, fed ad libitum a diet containing $24 \%$ protein and $2896.8 \mathrm{kcal} / \mathrm{kg}$ metabolize energy, the birds slaughtered and measurements had taken for the following traits : live body weight, carcass weight, dress percentage, breast part weight, thigh weight, heart weight, liver weight and total Intestine length. The correlation coefficients were calculated between the factors ( variety, sex and age ) and the traits included in the study using Spearman method, and regression coefficients were calculated between vital organs ( independent variable ) and productive traits ( dependent variable, also the predictive equation of significant regression was formulated, and the correlation between predictive and observed data calculated.

The statistical analysis performed according factorial experiment $2 \times 2 \times 3$ in randomized complete block design with three replicates, and the significance of differences among means tested by Least Significant Differences ( LSD) at $\mathrm{P}<0.05$.

\section{Results}

The statistical analysis of variance declares that the main effect of sex was highly significant effect $(\mathrm{P}<0.01)$ on live body weight, dress percentage, liver weight and gizzard weight, also there were highly significant effect $(\mathrm{P}<0.01)$ of the main effect of age on intestine length and gizzard weight, while the significant effect of variety restricted only on heart weight. The interaction among the different factors (variety, age and sex) showed significant effect between variety $\times$ sex on gizzard weight, and a significant interaction between ages $\times$ sex on liver weight.

Table 1. Effect of variety on weights(gm)of live body, carcass, breast and thigh, dress percentage, and vital organs in Japanese quail.

\begin{tabular}{lll}
\hline \multirow{2}{*}{ Traits } & Variety & \\
\cline { 2 - 3 } & White & Gray \\
\hline Body weight $(\mathrm{gm})$ & 168.29 & 170.60 \\
Carcass weight $(\mathrm{gm})$ & 113.18 & 114.44 \\
Dress Percent $(\%)$ & 67.63 & 67.58 \\
Breast weight $(\mathrm{gm})$ & 42.20 & 42.97 \\
Thigh weight $(\mathrm{gm})$ & 26.12 & 26.30 \\
Heart weight $(\mathrm{gm})$ & $1.52 \mathrm{a}$ & $1.37 \mathrm{~b}$ \\
Liver weight $(\mathrm{gm})$ & 4.50 & 4.60 \\
Gizzard weight $(\mathrm{gm})$ & 4.12 & 4.01 \\
Intestine length(cm) & 54.22 & 54.86 \\
Relative heart weight(\%) & $0.90 \mathrm{a}$ & $0.80 \mathrm{~b}$ \\
Relative liver weight(\%) & 2.60 & 2.60 \\
\hline
\end{tabular}

*Means with different letters significantly different at $\mathrm{P}<0.05$.

Table 1 represents the means of white and Gray varieties in productive traits, which there were no significant differences between them, that may be indicated to unimportant role of the color genes in these traits.

While the results showed significant differences between varieties in the heart weight and relative heart weight, hence it was 1.52 and 0.9 in white plumage variety and it was 1.37 and 0.8 in Gray plumage variety.

Table 2. Effect of ages on weights(gm) of live body, carcass, breast and thigh, dress percentage, and vital organs in Japanese quail.

\begin{tabular}{llll}
\hline \multirow{2}{*}{ Traits } & Ages & week & \\
\cline { 2 - 4 } & $\mathbf{6}$ & $\mathbf{8}$ & $\mathbf{1 0}$ \\
\hline Body weight $(\mathrm{gm})$ & 172.4 & 166.2 & 169.7 \\
Carcass weight $(\mathrm{gm})$ & 117.0 & 111.0 & 113.4 \\
Dress Percent $(\%)$ & 68.1 & 67.3 & 67.4 \\
Breast weight $(\mathrm{gm})$ & 44.8 & 41.8 & 41.2 \\
Thigh weight $(\mathrm{gm})$ & 26.3 & 25.5 & 26.9 \\
Heart weight $(\mathrm{gm})$ & 1.5 & 1.4 & 1.4 \\
Liver weight $(\mathrm{gm})$ & 4.5 & 4.5 & 4.7 \\
Gizzard weight $(\mathrm{gm})$ & $4.8 \mathrm{a}$ & $3.5 \mathrm{~b}$ & $3.9 \mathrm{~b}$ \\
Intestine length(cm) & $55.4 \mathrm{~b}$ & $48.7 \mathrm{c}$ & $59.5 \mathrm{a}$ \\
Relative heart weight & 0.9 & 0.9 & 0.8 \\
Relative liver weight & 2.6 & 2.6 & 2.7 \\
\hline
\end{tabular}

*Means with different letters significantly different at $\mathrm{P}<0.05$.

Also, there were no significant differences between measurements of traits in the different ages included in the study for all production traits (Table 2), especially body weight and dress percentage that is confirm suitable slaughter age is 6 weeks as practice in most commercial process. The effect of age on measurements of vital organs had shown in Table 6, there were significant differences among ages in the length of the intestine and gizzard weight.

From Table 3, the result showed significant differences between males and females in live body weight and dress percentage, and although the live body weight of the female is greater than the male, but the dress percentage of the male was greater, that is may be result from the discard of the female reproductive system which larger than male reproductive system, this result agree with the result found previously by Hassan et al. ${ }^{4}$ There were significant differences between male and female in all measurements of vital organs exclude heart weight, hence female has a significant increase in all measurements of vital organs with compared to male, and this may be necessary for egg production, this results agree with the result found by Daikwo et al. ${ }^{5}$ and Anna et al. ${ }^{9}$.

Table 3. Effect of sex on weights(gm)of live body, carcass, breast and thigh, dress percentage, and vital organs in Japanese quail.

\begin{tabular}{lll}
\hline \multirow{2}{*}{ Traits } & Sex & \\
\cline { 2 - 3 } & Male & Female \\
\hline Body weight $(\mathrm{gm})$ & $154.79 \mathrm{~b}$ & $184.10 \mathrm{a}$ \\
Carcass weight $(\mathrm{gm})$ & 112.45 & 115.17 \\
Dress Percent $(\%)$ & $72.62 \mathrm{a}$ & $62.58 \mathrm{~b}$ \\
Breast weight $(\mathrm{gm})$ & 41.30 & 43.87 \\
Thigh weight $(\mathrm{gm})$ & 26.04 & 26.38 \\
Heart weight $(\mathrm{gm})$ & 1.42 & 1.47 \\
Liver weight $(\mathrm{gm})$ & $3.22 \mathrm{~b}$ & $5.88 \mathrm{a}$ \\
Gizzard weight $(\mathrm{gm})$ & $3.60 \mathrm{~b}$ & $4.53 \mathrm{a}$ \\
Intestine length(cm) & $49.56 \mathrm{~b}$ & $59.53 \mathrm{a}$ \\
Relative heart weight(\%) & $0.90 \mathrm{a}$ & $0.80 \mathrm{~b}$ \\
Relative liver weight $(\%)$ & $2.10 \mathrm{~b}$ & $3.20 \mathrm{a}$ \\
\hline
\end{tabular}

*Means with different letters significantly different at $\mathrm{P}<0.05$.

There was only a significant interaction effect between 
variety $\times$ sex on gizzard weight, while there were no significant differences for this interaction in other measurements of vital organs (Table 4). The interaction between ages and sex showed the only significant effect in liver weight and the relative liver weight (Table 5), while there were no significant effect of this interaction in other productive and vital organs included in the study.

The statistical analysis appeared no significant effect of the interaction among the three factors (variety $\times$ sex $\times$ age) in all productive and the measurements of vital organs, so the data on these interactions did not appear in the results had shown here.

Table 4. Effect of interaction between varieties and sex on weights of heart, liver, gizzard, intestine length, relative weights of heart and liver in Japanese quail.

\begin{tabular}{lllll}
\hline \multirow{2}{*}{ Traits } & White & Gray & \\
\cline { 2 - 5 } & Male & Female & Male & Female \\
\hline Heart weight & 1.5 & 1.5 & 1.3 & 1.4 \\
Liver weight & 3.5 & 5.5 & 2.9 & 6.3 \\
Gizzard weight & 3.9 & 3.3 & 4.4 & 4.7 \\
Intestine length & $50.2 \mathrm{c}$ & $58.3 \mathrm{~b}$ & $48.9 \mathrm{~d}$ & $60.8 \mathrm{a}$ \\
Relative heart weight & 1.0 & 0.9 & 0.9 & 0.7 \\
Relative liver weight & 2.2 & 3 & 1.9 & 3.3 \\
\hline
\end{tabular}

*Means with different letters significantly different at $\mathrm{P}<0.05$.

Table 5. Effect of interaction between ages and sex on weights(gm) of liver, gizzard, relative weight of liver in Japanese quail.

\begin{tabular}{lllll}
\hline Ages & Sex & Liver & Relative & Gizzard \\
\hline week & & weight & liver weight & weight \\
\hline 6 & Male & $3.90 \mathrm{bc}$ & $2.40 \mathrm{bc}$ & 4.22 \\
& Female & ab 5.14 & b 2.8 & 5.35 \\
8 & Male & $2.73 \mathrm{c}$ & $1.80 \mathrm{c}$ & 3.03 \\
& Female & a 6.24 & a 3.4 & 3.99 \\
10 & Male & $3.04 \mathrm{bc}$ & $2.00 \mathrm{c}$ & 3.56 \\
& Female & $6.28 \mathrm{a}$ & $3.40 \mathrm{a}$ & 4.25 \\
\hline
\end{tabular}

*Means with different letters significantly different at $\mathrm{P}<0.05$.

Table 6. Correlation coefficients between variety, sex, age and some productive traits in Japanese quails.

\begin{tabular}{lllll}
\hline & body & Carcass & Dress & Breast \\
\cline { 2 - 5 } & weight & weight & percentage & weight \\
\hline Variety & 0.064 & -0.003 & 0.027 & 0.123 \\
Age & -0.160 & -0.118 & 0.026 & -2.110 \\
Sex & $0.759 * *$ & 0.163 & $-0.850 * *$ & 0.225 \\
\hline
\end{tabular}

** Mean correlation is significant at $\mathrm{P}<0.01$.

Table 7. Correlation coefficients between variety, sex, age and some vital organ measurements in Japanese quails.

\begin{tabular}{lllll}
\hline & Heart & Liver & Gizzard & Intestine \\
\cline { 2 - 5 } & weight & weight & weight & length \\
\hline Variety & -0.294 & -0.048 & -0.078 & 0.064 \\
Age & -0.107 & -0.013 & $-0.383^{*}$ & 0.184 \\
Sex & 0.059 & $0.816^{* *}$ & $0.519^{* *}$ & $0.637 * *$ \\
\hline
\end{tabular}

* Mean correlation is significant at $\mathrm{P}<0.05$

**Mean correlation is significant at $\mathrm{P}<0.01$.

Correlation coefficients between the factors (variety, age and sex) and productive traits presented in Table 6 , the results showed highly significant correlation between sex and each of live body weight and dress percentage. and the correlation coefficients between those factors and vital organs were presented in Table 7, the results showed a significant negative correlation coefficient between age and gizzard weight, and there were highly significant positive correlation between sex and each of liver weight, gizzard weight and intestine length.

The regression coefficient between vital organs as independent variable and each of body weight, carcass weight, dress percentage and breast weight calculated in the males as appear in Table 8 showed highly significant regression $(\mathrm{P}<0.01)$ of body weight on gizzard weight, the prediction equation according to this estimation is:

$$
\mathrm{Y}^{\wedge}=125.514+8.123 \mathrm{X}
$$

Where $\mathrm{Y}^{\wedge}$ refer to expected live body weight, and $\mathrm{X}$ refer to observed gizzard weight in the bird, estimation of the correlation coefficient. between expected values and observed body weight was highly significant and estimated 0.687 , beside significant regression $(\mathrm{P}<0.05)$ of carcass weight on gizzard weight, the prediction equation according to this estimation is:

$$
\mathrm{Y}^{\wedge}=91.64+5.7 \mathrm{X}
$$

Where $\mathrm{Y}^{\wedge}$ refer to expected carcass weight, and $\mathrm{X}$ refer to observed gizzard weight in the bird.

Table 8. Regression coefficient between vital organs (independent variables) and productive traits (dependent variable) in male Japanese quails.

\begin{tabular}{lllll}
\hline $\mathbf{y}$ & Body & Carcass & Dress & Breast \\
\hline $\mathbf{x}$ & weight & weight & $\mathbf{( \% )}$ & weight \\
\hline Heart & 10.32 & 1.18 & -3.92 & 6.69 \\
weight & \pm 10.20 & \pm 9.74 & \pm 2.95 & \pm 4.34 \\
Liver & 5.11 & 2.97 & -0.44 & 1.21 \\
weight & \pm 2.58 & \pm 2.56 & \pm 0.84 & \pm 1.23 \\
Gizzard & $8.12^{* *}$ & $5.77 *$ & -0.06 & 1.39 \\
weight & \pm 2.07 & \pm 2.26 & \pm 0.86 & \pm 1.23 \\
Intestine & 0.24 & -0.02 & -0.12 & -0.06 \\
length & \pm 0.36 & \pm 0.33 & \pm 0.10 & \pm 0.16 \\
\hline
\end{tabular}

* Mean regression is significant at $\mathrm{P}<0.05$

** Mean regression is significant at $\mathrm{P}<0.01$.

Estimation of correlation coefficients between expected values and observed carcass weight was significant and estimated 0.521 , which gave indicator for reliable work of the prediction equation. The other regression coefficients showed on significant estimations in all cases.

The results in Table 9 represented regression coefficients between vital organs as independent variable and each of body weight, carcass weight, dress percentage and breast weight calculated in the females, the results showed Significant regression $(\mathrm{P}<0.05)$ of carcass weight on heart weight of females, the prediction equation according to this estimation is:

$$
\mathrm{Y}^{\wedge}=84.356+20.936 \mathrm{X}
$$

Where $\mathrm{Y}^{\wedge}$ refer to expected carcass weight, and $\mathrm{X}$ refer to observed heart weight in the female, the correlation 
coefficient between expected values and observed carcass weight in females was significant and estimated 0.555 , while the other regression coefficient estimation had no significant effect.

Table 9. Regression coefficient between vital organs (independent variables) and productive traits (dependent variable) in female Japanese quails.

\begin{tabular}{lllll}
\hline $\mathbf{y}$ & Body & Carcass & Dress & Breast \\
\hline $\mathbf{x}$ & weight & weight & $\mathbf{( \% )}$ & weight \\
\hline Heart & 20.07 & $20.94^{*}$ & 4.49 & 8.59 \\
weight & \pm 14.35 & \pm 9.50 & \pm 3.53 & \pm 4.79 \\
Liver & 4.29 & 2.39 & -0.19 & 0.75 \\
weight & \pm 2.22 & \pm 1.65 & \pm 0.60 & \pm 0.83 \\
Gizzard & 5.48 & 1.90 & -0.93 & 0.75 \\
weight & \pm 3.95 & \pm 2.95 & \pm 0.99 & \pm 1.43 \\
Intestine & 0.81 & 0.20 & -0.17 & -0.04 \\
length & \pm 0.47 & \pm 0.36 & \pm 0.12 & \pm 0.18 \\
\hline
\end{tabular}

* Mean regression is significant at $\mathrm{P}<0.05$

** Mean regression is significant at $\mathrm{P}<0.01$.

\section{Discussion}

The results of this study showed a significant effect between white and Gray colors with respect to productive traits and vital organs except heart weight and its relative weight, and the result may reflect the equality in performance of these varieties in Iraqi environment.

The effect of ages included in our study showed no significant differences among them in all production traits, these results disagree with observations found by Akram et al. ${ }^{10}$, so the best age for slaughter is 6 week age and there was no benefit to stay the birds to advance ages, although there was significant differences among ages in gizzard weight and intestine length but there was no reflected of them in body weight or carcass weight.

The effect of sex on body weight obviously notice, hence female quails had significantly higher body weight, liver weight, gizzard weight and intestine length compared with males, but there were no significant differences between males and females in dress percentage. The previous studies estimated high dress percentage in the Japanese quails ranged from $65.65 \%$ ( Hassan et al. $^{4}$ ) and $77 \%$, which found by Jones et al. ${ }^{11}$ the high value of dress percentage in Japanese quails give an indicator for their high efficiency and suitable choice for meat production. The results of this study showed no significant differences between sexes in term of thigh weight, this result agrees with vali et al. ${ }^{7}$ and disagree with Alkan et al. ${ }^{12}$ who reported that quail males showed significantly $(\mathrm{P}<0.01)$ higher thigh percent of body weight than females.

The results showed highly positive correlation coefficient between sex and body weight, liver weight, gizzard weight and intestine length, hence the high value of those traits associated with females than males, these results agree with Alkan et al. ${ }^{12}$.

The regression coefficient of body weight on gizzard weight was highly significant in male only, but not significant in female, in spite of the significant high value of gizzard weight in female.

\section{Conclusion}

According to the results of this study, there was equality in performance of white and Gray varieties for meat production in Iraqi environment. And the highly significant correlation between gizzard weight and body weight may reflect the importance of the function of this part in the growth of the bird.

\section{References}

[1] Hassan, K. H. 2011. Poultry Breeding. 1st Edition, Diyala University Press. Iraq.

[2] Sarabmeet Kaur, A. B. Mandal, K. B. Singh, M. M. Kadam.2008. The response of Japanese quails (heavy body weight line) to dietary energy levels and graded essential amino acid levels on growth performance and immunocompetnce. Livest. Sci., (2008), doi: 10.1016/j.livsci.12.019

[3] Hassan, K. H. 2013. Evaluation of productive performance of Japanese quail in summer of Iraq. Diyala Agricultural Science Journal, 5 (2): $69-80$.

[4] Hassan, K. H., A. A. Ahmad, T. A. Dawood, and N. K. Fadil. 2013. Study of dress percentage and relative weights of carcass parts in various ages of Japanese quail in Iraq. Diyala Agricultural Science Journal, 5 (2):92-103.

[5] Daikwo, S. I., O. M. Momoh and N. I. Dim. 2013. Heritability Estimates of, Genetic and Phenotypic Correlations among Some Selected Carcass Traits of Climate. Journal of Biology, Agriculture and Healthcare, Vol.3, No.5: 60 - 65 .

[6] Nasrollah Vali, M.A. Edriss and H. Moshtaghi. 2006. Comparison of Egg Weight Between Two Quail Strains. International Journal of Poultry Science. 5 (4): 398-400.

[7] Vali, N., M. A. Edriss and H. R. Rahmani. 2005. Genetic parameters of body and carcass traits in two quail strains. Int. J. Poult. Sci. 4(5): 296-300.

[8] Berri, C. 2004. Breeding and quality of poultry. In, Mead G.C. (Ed): Poultry Meat Processing and Quality. CRC Press Cambridge., 21-33.

[9] Anna W., K. Dariusz and C. Joanna. Body conformation and morphometry of some internal organs of Pharaoh quail of different ages. Journal of Central European Agriculture, 2013, 14(2), p.358-368.

[10] Akram M., J. Hussain, S. Ahmad, S. Mehmood, A. Rehman, A Iqbal and M. Usman. 2013. Study of Body Measurements and Slaughter Characteristics in Japanese quail as Influenced by Age. Scientific Journal of Zoology, 2(3) 23-26.

[11] Jones J. E., B. L. Hughes and K. K. Hale. 1979. Coturnix Di quail, carcass yield. Poult. Sci. 58:1647-1648.

[12] Alkan, S., K. Karabag, A. Galic, T. Karsli and M. S. Balcioglu. 2010. Determination of Body Weight and Some Carcass Traits in Japanese Quails (Coturnix coturnix japonica) of Different Lines. Kafkas Univ. Vet. Fak. Derg., 16(2) 277-280. 